\title{
Technical Design rules of ETFE membrane structures using the tensile strength measurements in production and development
}

\section{$X$ International Conference on Textile Composites and Inflatable Structures - STRUCTURAL MEMBRANES 2021}

\author{
Torsten Balster*, Delche Lazarev ${ }^{\dagger}$, Bernd von der Kammer ${ }^{\dagger}$ and Carl Maywald ${ }^{\dagger}$ \\ *Vector Foiltec GmbH, Steinacker 3, D-28717 Germany, torsten.balster@vector-foiltec.com, web \\ page: http://www.vector-foiltec.com
}

\begin{abstract}
The Euro Code 0 (EN 1990) is the common basis of the European Union for structural design of any building. It should harmonize all national rules to unified European design rules, even though some EU countries are using the National Annex to consider local particularities.

However, the Euro Code itself is only for guidance to develop the technical specification for the structural design of the ETFE membranes. It is possible to create a simple model for the resistance of the ETFE membrane and its joints by using the measurements of the tensile strength. One can start with the definition of the consequences of a failure of the membrane structure, which lead easily to the execution classes. In order to verify this execution, the manufacturer obligates itself to comply to a certain inspection level. Beside these more informative rules, the material properties of ETFE foils and their joints are characterized by a statistical distribution due to immanent production inaccuracies. Whereas the mechanical properties of the foil, which are defined by the extrusion and the properties of the polymer chain, is not dominating the resistance of the membrane structure, it could be shown, that the weldings of the foil determine the final ULS value of the membrane. The statistical distribution of the tensile strength of the weld is defined by the variation of the welding process, i.e. the operation principle and the parameters of the welding machines.

In this presentation the statistical parameters for the design value will be derived on the basis of the Eurocode 0 . Using the statistical results of the quality control of our production the maximum design values in resistance could be estimated. Vice versa, one can easily obtain the minimum values for the production quality control, i.e. the 5\%-quantiles and mean values of tensile strength of the welding seams.
\end{abstract}

\section{REFERENCES}

[1] DIN EN 1990:2010-12 Basis of structural design. Berlin, Germany, Beuth (2010). 